\title{
Utilização de Computação Humana para Mapear Oligarquias Políticas no Brasil
}

\author{
Maria Clara Tenório Pestana \\ ${ }^{1}$ Universidade Federal da Paraíba \\ João Pessoa, PB, Brasil \\ clarapestana91@gmail.com
}

\begin{abstract}
History of politics in Brazil revels that, since the times of Captaincy, groups of families are responsible for most of elected candidates in Brazil. There was not found any information system that identifies these connections and measures the size of these families. This study uses Human Computation for mapping families of politicians that are perpetuating. This research gathers data from contributors to identify whether or not two candidates are relatives. Personal data from politicians are extracted from electoral data repository of Tribunal Superior Eleitoral that provides this information for scientific researches. Contribuaś platform aids the data gathering and outcomes usersánswers. The resultant data, when processed, can be used for mapping data structured in graphs that compose family trees of the political oligarchs in Brazil. The size of oligarchs is represented by the dimention of those trees.
\end{abstract}

Resumo. A história política do Brasil revela que, desde a época das capitanias hereditárias, grupos de famílias são responsáveis por grande parte dos candidatos eleitos no Brasil. Não foi encontrado nenhum meio de informação que identifique essas conexões e mensure o tamanho dessas famílias. Este trabalho utiliza Computação Humana para realizar o mapeamento das famílias de políticos que estão se perpetuando no poder, dispondo um meio para coletar os dados provenientes dos contribuintes que identificam se dois candidatos eleitos são ou não parentes. Os dados pessoais dos políticos são extraídos do repositório de dados eleitorais disponibilizados pelo TSE para fins científicos. A coleta de dados referente ao parentesco é realizada através da plataforma Contribua que gera os dados das classificações feitas pelos usuários. Quando processados, esses dados são estruturados em grafos que compõem as árvores genealógicas das oligarquias políticas no Brasil. O tamanho das oligarquias é representado pela dimensão dessas árvores.

\section{Introdução}

A transferência de poder de uma geração à outra da mesma família provoca a formação de uma base parlamentar avessa a mudanças significativas [SCHOENSTER 2014]. A pesquisa feita pela ONG Transparência Brasil revela que a medida em que o percentual de deputados com parentes na política cresce, diminuem o IDH e a participação do Estado no PIB nacional e aumenta a sua taxa de analfabetismo [DUARTE, 2014]. Resultados como este, faz com que se queira identificar quem são os membros das oligarquias 
políticas. Dados que são de conhecimento do povo é objeto principal de pesquisa em Computação Humana, pois este é um novo modelo de computação distribuída que utiliza da cognição e da capacidade de raciocínio de seres humanos para resolver problemas que os computadores ainda não podem resolver de forma satisfatória [OLIVEIRA, PONCIANO, ANDRADE e BRASILEIRO 2013]. Por esse motivo, este trabalho visou utilizar a técnica de computação humana que é capaz de coletar dos usuários informações a cerca do parentesco entre políticos. Como resultado, a ferramenta desenvolvida irá mapear o parentesco entre pessoas que ocupam ou já ocuparam cargos políticos.

\section{Trabalhos Relacionados}

Existem diversas publicações sobre pesquisas estatísticas que fazem uso de dados eleitorais publicados na internet [SCHOENSTER 2014][DUARTE 2014][BRAMBOR e CENEVIVA 2012][ALVES e DINIZ 2004], como também artigos que dissertam sobre consequências da perpetuação política na sociedade [NASCIMENTO 2009][LADEIRA 2009][MARIANO 2005][CANEDO 1997][FARIAS 2014]. Apesar da notável quantidade de textos e gráficos sobre esse tema, ainda não existe uma solução confi' avel na Internet capaz de identificar quem são os membros e o quão grande é o nível de oligarquias no Brasil. Tendo em vista essa situação, este trabalho buscou criar um meio que identifique os membros pertencentes à essas famílias e os mapeiem em árvores genealógicas posicionadas segundo o local do território nacional de onde eles são provenientes.

\section{Objetivos}

Esta pesquisa tem por objetivo geral utilizar o conceito de computação humana para geração de dados estruturados em forma de grafos que servirão para identificação e mapeamento de oligarquias brasileiras. Os objetivos específicos deste trabalho foram os seguintes:

- Analisar o repositório de dados eleitorais do TSE para obter informações acerca de políticos eleitos desde 1945.

- Elaborar um sistema de computação humana que armazena sugestões de parentesco entre atuais e antigos políticos em verdadeiros e falsos.

- Exibir o mapa do Brasil com as árvores que forem sendo formadas.

\section{Metodologia}

O tema do presente trabalho está concentrado na área de Análise de Dados, por se tratar do desenvolvimento de um sistema web onde usuários classificam o grau de parentesco entre políticos. O sistema web, nesse caso, utiliza Computação Humana para coleta de dados sobre o grau de parentesco. Na computação humana, ao invés de o ser humano fazer uso do computador para resolver problemas - como acontece na computação 'tradicional' - o computador coloca uma pessoa ou grupo de pessoas para resolver o problema, posteriormente agregando os resultados e obtendo a solução final [SCHNEIDER, SOUZA e MORAES 2011]. Para coletar o máximo de dados possíveis, foi estudado o conceito de "multidões" na qual uma quantidade massiva de dados provenientes de centenas de usuários são capturados por meio de um sistema que faz uso da técnica de "crowdsourcing" ou "crowd-source" [HOWE 2006]. O grau de parentesco entre políticos poderá então ser analisado através de um mapeamento genealógico que servirá na identificação 
de oligarquias políticas. Os trabalhos relacionados apresentados na seção 2 deste artigo, mostram que as oligarquias políticas vêm sendo objeto de pesquisa na causa de alguns problemas sociais brasileiros. Os tópicos que se seguem visam explanar e estender a compreensão a cerca dos recursos utilizados para construção do mapeamento. A ideia inicial foi desenvolver um sistema web de computação humana para que os usuários pudessem classificar o grau de parentesco dos políticos. O sistema apresentaria para seus usuários os dados de dois políticos e pediria para o usuário informar se tais políticos são ou não parentes e, em caso afirmativo, indicar o grau de parentesco. Com isso, seria possível montar árvores genealógicas dos políticos no Brasil. Os dados dos políticos eleitos desde 1945 estão disponíveis no site do TSE (Tribunal Superior Eleitoral). Na fase de desenvolvimento, foi necessário fazer o estudo dos dados coletados no repositório eleitoral do TSE. Para obter os dados referentes aos nomes, locais e cargos associados aos referidos políticos, os dados do TSE foram armazenados em um banco de dados SQL que torna mais rápida a busca por cada uma das informações e a filtragem dos dados. Nesse caso, o administrador deve supor os políticos que possam ser parentes, baseado em pesquisas e sobrenomes, e checar se os nomes estão armazenado nos registros do TSE. A partir daí inicia-se o mapeamento que conta com a ajuda da população através do sistema Contribua. As fotos utilizadas no projeto são as fotos utilizadas nas urnas eletrônicas que foram disponibilizadas pelo TSE. Essas fotos foram encontradas na internet em portais como o da UOL e do próprio TSE.

\subsection{Plataforma Contribua para Computação Humana}

O sistema foi construído por meio de um servidor web que armazena os dados do repositório eleitoral do TSE sobre todos os candidatos das eleições encontradas na base do TSE. Para armezar esses dados, foi utilizado o servidor da AWS (Amazon Web Service) que é acessado remotamente. Através dele foi possível criar o banco de dados no gerenciador phpMyAdmin onde os dados foram filtrados e armazenados em uma tabela na qual seus registros correspondem à todos os candidatos que já foram eleitos. Desses políticos eleitos, retira-se manualmente dois nomes do banco de dados e atribui-se uma sugestão referente ao seu parentesco: [nome 1] [nome 2] [parentesco]. Dessa maneira tem-se a garantia que os políticos inseridos no sistema estão devidamente registrados no TSE. Este relacionamento é inserido manualmente na planilha Google Spreadsheet, a qual é importada para aplicação Contribua que utiliza o framework Pybossa ${ }^{1}$. O Contribua é uma plataforma de ciência cidadã mantido pelo Laboratório de Sistemas Distribuídos (LSD) UFCG. A plataforma Contribua ${ }^{2}$ permite o administrador criar projetos e também tem a funćão de atrair voluntários para contribuir com os projetos. Cada projeto consiste de uma aplicação na qual o administrador deve inserir um nome, slug e descrição. Depois, ele deve importar as tarefas através de arquivos CSV públicos na web ou Google Drive Spreadsheet. As tarefas serão visualizadas pelos usuários da plataforma e para isto, é necessário configurar o visualizador de tarefas que é um simples editor HTML + Javascript. Esse editor codifica a associação de cada tarefa com as respostas dadas pelos usuários para gerar um arquivo $\mathrm{JSON}^{3}$ contendo as respostas que foram inseridas. Nesse código, é possível identificar qual foi o julgamento do usuário para o relacionamento entre "Politico 1 é Politico 2".

\footnotetext{
${ }^{1}$ http://pybossa.readthedocs.org/en/latest/

${ }^{2}$ https://contribua.org/pybossa/about

${ }^{3}$ https://www.contribua.org/pybossa/app/politicos_paraiba/40373/results.json
} 


\subsection{Criação de Grafos no Gephi}

O programa Gephi ${ }^{4}$ é utilizado para criação de grafos e é através dele que é realizado o mapeamento dos políticos. O Gephi, por sua vez, lê o arquivo de grafos em formato GEXF. Por isso é necessário que se transforme os dados com as respostas dos usuários do formato JSON para GEXF, exibindo no grafo aqueles relacionamentos votados pelos usuários em sua maioria como "verdadeiros".

\subsection{Transformação de JSON para GEXF}

Todas as respostas enviadas pelo usuários na plataforma Contribua são armazenadas no formato JSON que precisa ser convertida para construção do grafo de políticos no formato GEXF. A implementação da conversão foi realizada no Eclipse na linguagem JAVA. Para extrair as informações do arquivo JSON, foi utilizada a biblioteca "JSON simple". Os dados utilizados são: estado, município, nomes e parentesco. Então, o JSON deve ser convertido para o formato GEXF que é um formato possível de ser aberto no programa Gephi. Para criar o arquivo GEXF, foi utilizado a biblioteca gexf4j. O programa recebe como entrada o arquivo de entrada JSON que foi gerado na plataforma Contribua. Em seguida, calcula a quantidade de julgamentos armazenados para cada relação de parentesco entre verdadeiros ou falsos. Se a maioria dos votos é verdadeira, este relacionamento vai ser mapeado no arquivo GEXF. Durante o processo de construção do arquivo GEXF, é necessário conhecer as coordenadas onde se localiza o político que está sendo mapeado. Existe a informação de nome do município, porém não existe dados sobre a latitude e longitude desse município. Por isso, foi necessário implementar uma função baseada na aplicação "get latlng position" retirada do portal javaservletsjspweb.in desenvolvida por Santhosh Reddy Mandadi. Por isso, o programa para funcionar necessita de conexão com a internet. Como existem muitos políticos para um município, ao importar o grafo para o mapa, iria acontecer uma sobreposição. Por isso, para cada latitude e longitude gerada, coloca-se um fator aleatório para alterar sutilmente a posição do nó, evitando a sobreposição de nós no grafo. Como consequência, toda vez que o programa é executado, ele muda a posição dos nós gerando um grafo diferente devido a esta aleatoriedade. Ao executar o programa, é gerado o arquivo GEXF de nome "saída.gexf". Esse arquivo de saída ao ser aberto no Gephi, mostra o grafo em forma de árvore com os nodes referentes a cada politico e suas conexões.

\subsection{Exportação para Google Maps}

Ao abrir o grafo, já no formato GEXF, no Gephi, define-se o GeoLayout de acordo com os atributos de latitude e longitude do grafo. Além do GeoLayout, é aplicada também a operação de modularidade. A partir dessa operação, é possível fazer com que os nós que são conectados recebam uma determinada cor, tornando mais fácil de visualizar a família. é possível fazer outras diversas operações como alterar o tamanho do node de acordo com seu aspecto de centralidade. A partir do plugin do Gephi, pode ser inserido o Geolayout que vai posicionar as nodes de acordo com suas coordenadas na projeção "Mercator" escala: 1000. Projeção utilizada pelo Google Maps. Em seguida, utilizando o plugin "ExporttoEarth" é possível exportar o grafo como formato KMZ para o Google Earth. O Google Earth oferece uma ótima visualização das árvores genealógicas dispostas

\footnotetext{
${ }^{4}$ http://gephi.github.io/users/download/
} 
no mapa. No Google Earth, o arquivo pode ser salvo como KML que é um tipo de arquivo que pode ser importado no Google Maps. O Google Maps disponibiliza um cógico HTML para compartilhar o mapa na Web.

\section{Discussão}

É importante ressaltar que o Pybossa implementa critérios de restrições que impede que um usuário insira mais de uma resposta para uma mesma tarefa. Em caso de usuários anônimos (não logados), ele restringe através do reconhecimento da máquina utilizada para computar a resposta, sendo esta característica um ponto forte apresentado pelo uso do Contribua. O ponto fraco da plataforma é o fato das importações de tarefas serem feita de maneira manual. Outro ponto que vale ser ressaltado é que, para o bom funcionamento do crowdsorcing, o usuário não pode controlar as tarefas que ele quer responder. Por isso, para cada categoria de tarefas que queiramos apresentar ao usuário, um novo projeto deverá ser criado, por exemplo: um projeto para usuários que queiram votar em parentescos da Paraíba, outros de Pernambuco, etc. Ao clicar em uma categoria, as tarefas serão exibidas para os colaboradores. O projeto "Políticos" ${ }^{5}$ está criado na plataforma "Contribua.org" e aberto para receber entradas "verdadeiro" ou "falso" para 16 relacionamentos de políticos da Paraíba. O sistema precisa apenas ser alimentado com os dados referentes aos parentesco entre políticos. Devido ao grande número de políticos, esse preenchimento será feito a longo prazo, mas a cada nova entrada julgada como verdadeira, uma nova árvore será plotada no mapa. Com passar do tempo, o mapa do Brasil ficará todo preenchido com árvores de oligarquias políticas. As pessoas que forem dar sua contribuição vão poder olhar os relacionamentos de parentescos no mapa que estão sendo julgados como verdadeiro. Caso os usuários não saibam a resposta para um relacionamento, existe a opção "Não Sei”.

\section{Considerações Finais}

Apesar de existirem tantas publicações sobre dados estatísticos eleitorais e textos a respeito da perpetuação política, não encontra-se na Internet uma fonte confiável que disponibilize dados a cerca de quem faz parte das oligarquias brasileiras. No entanto, a popularidade dessas famílias é tão grande que faz com que seja possível mapea-los através do uso da computação humana em plataformas que atraiam voluntários como é o caso do Contribua. Esse mapeamento identifica quem são os membros aparentados e mensura o tamanho desses clãs de acordo com os níveis que chegam cada árvore genealógica representada. Essa é uma forma de representação de dados nova que pode interessar pesquisadores que buscam um instrumento de identificação de oligarquias políticas. Além disso, esse trabalho contribui com o desenvolvimento da plataforma Contribua a qual ainda está em fase de testes e necessita de retorno por parte de quem o utiliza, principalmente pelo fato de ainda ter poucos projetos implementados.

\subsection{Trabalhos Futuros}

O administrador do sistema é quem insere as relações de parentesco para serem votadas na tarefas do Contribua. Como trabalho futuro, os usuários que queiram o auxiliar com sugestões para ser inseridas no projeto do Contribua, poderão as enviar em um formulário.

\footnotetext{
${ }^{5}$ https://contribua.org/pybossa/app/tcc/newtask
} 
Os nomes dos políticos deverão ser escolhidos através do auto-complete ou tabela de dados, que retornarão os dados idêntico ao do repositório do TSE, evitando que seja inserido "lixo". Considera-se também implementar um algoritmo que analise automaticamente sobrenomes e calcule um limiar de similaridade ou distância de edição para sugerir novos parentescos para serem validados. No Contribua e nas sugestões, os usuários devem poder enviar referências ou justificativa para o seu voto. Um número mínimo de votos verdadeiros deverão ser verificados antes de plotar o relacionamento no mapa e a votação para tal relacionamento deverá ser encerrada, evitando assim respostas tendenciosas de pessoas que tenham acessado o mapa previamente. Outro trabalho futuro é fazer a geração automática dos mapas a partir de métodos de agendamento Cron Job, assim como automatizar a exibição de grafos com ferramentas interativas como d3js 6 . Também seria importante criar um perfil dos políticos com informações de seus parentescos. Outras análises de dados também poderiam ser feitas através de um processo similar ao descrito nesse trabalho, como por exemplo, mapeamento de alianças entre grupos políticos.

\section{Referências}

ALVES, José DINIZ, Eustáquio. PARTICIPAÇÃO DAS MULHERES NAS ELEIÇÕES DE 2004: AVALIAÇÃO DA POLíTICA DE COTAS NO BRASIL, 2004.

BRAMBOR, Thomas and CENEVIVA, Ricardo.Reeleição e continuísmo nos municípios brasileiros.Novos estud. - CEBRAP [online]. 2012, n.93, pp. 0921. ISSN 0101-3300. Disponível em: [http://dx.doi.org/10.1590/S010133002012000200002] Acesso em 24.02.2015.

CANEDO, Letícia Bicalho. As metáforas da família na transmissão do poder político: questões de método. Cad. CEDES, Campinas, v. 18,n. 42, Aug. 1997.

DUARTE, Alexandre Nóbrega. Não vote nos parentes! [online] 2014. Disponível em: [http://alexandre.ci.ufpb.br/nao-vote-nos-parentes/]. Acessado em 13.02.2015

FARIAS, Lazaro Alves. Eleição da Paraíba serviu para manter oligarquias no Poder. [online] 2014. Disponível em: [http://www.lazarofarias.com.br/2014/10/eleicaomantem-poder-de-familias-na.html]. Acessado em: 28.12.2014

HOWE, Jeff. The Rise of Crowdsourcing. 2006.

LADEIRA, Francisco Fernandes. 2009. As relações políticas entre as famílias Bias Fortes e Andrada na cidade de Barbacena: da formação da poderosa aliança à criação do mito da acirrada rivalidade. Mal-Estar e Sociedade. 2009 - p. 55-76.

MARIANO, Serioja Rodrigues Cordeiro. Gente opulenta e de boa linhagem: família, política e relações de poder na Paraíba - Recife, 2005. 284 p.

NASCIMENTO, Lerisson C. 2009. Notas sobre poder local: a família Rosado e a política em Mossoró/RN. Cadernos de Campo n. 12200 9-p. 61-73.

OLIVEIRA, Jeymisson; PONCIANO, Lesandro; ANDRADE, Nazareno; BRASILEIRO, Francisco. Estratégias de Obtenção de um Item Máximo em Computação por Humanos. In: Simpósio Brasileiro de Redes de Computadores e Sistemas Distribuídos - SBRC, 31., 2013, Campina Grande.

SCHNEIDER, Daniel; SOUZA, Jano de; MORAES, Katia. Multidões: a nova onda do CSCW? 2011.

SCHOENSTER, Lauren. Clãs Políticos no Congresso Nacional. [online] 2014. Transparência Brasil. Disponível em: [http://www.excelencias.org.br/docs/parentes.pdf]. Acessado em: 13.02.2015

\footnotetext{
${ }^{6}$ http://d3js.org/
} 